\title{
O Pai Presente: O Desvelar da Paternidade em Uma Família Contemporânea ${ }^{1}$
}

\author{
Aguinaldo José da Silva Gomes \\ Vera da Rocha Resende ${ }^{2}$ \\ Universidade Estadual Paulista Julio de Mesquita Filho - Bauru
}

\begin{abstract}
RESUMO - O objeto deste estudo é a figura concreta de um pai, presente em sua corporalidade e afetividade, que se depara com a demanda subjetiva, advinda da exigência de revisão de seu papel no mundo contemporâneo. Buscamos encontrar a paternidade que acolhe e convive com o processo de transformações em marcha: o pai que transita entre valores novos e arcaicos. O acesso a este conhecimento se deu através do método clínico de pesquisa, com apoio da psicanálise. Sem submeter os participantes ao tratamento psicanalítico, aplica seus conceitos na interpretação de fenômeno que tem dimensão subjetiva e também, social. Adotamos a entrevista como principal instrumento e a análise qualitativa enquanto estratégia, por permitir relevância à fala do entrevistado e dela extrair o dado significativo para nossas indagações.
\end{abstract}

Palavras-chave: paternidade; dinâmica familiar; desenvolvimento psico-afetivo.

\section{The Present Father: Discovering the Fatherhood in a Contemporary Family}

\begin{abstract}
This study focus on the real father figure present in his bodily and affectiveness, who has to face a subjective demand that came from the requirements of reviewing his role in the contemporary world. We looked for the paternity that refuge and lives together with the transformation process which transit through news and archaic values. The access to this knowledge was feasible through a clinical research method with the psychoanalysis support. Without submitting the participants into a psychoanalytical treatment, this study applies the psychoanalysis concepts on the interpretation of a subjective and social dimension phenomenon. We adopted the interview practice as the main tool and the qualitative analysis as strategy, in order to permit relevance to the interviewed speaking and extract from it the significant datum to our indagations.
\end{abstract}

Key words: paternity; dynamics family; development psychic-affective.

Em período recente de nossa história ${ }^{3}$, o homem encontrava dificuldades para separar sua individualidade das funções de pai. Manteve-se protegido no silêncio, comprometedor de toda possibilidade de diálogo com a família, especialmente com os filhos. Foi sempre apoiado pela cultura que, sendo patriarcal, reservou-lhe lugar acima da trama doméstica constituída, sobretudo pela mulher e pela criança. Esta situação vem-se modificando, lenta e progressivamente, sob a égide de transformações mais amplas, em cujo fluxo imbricam-se, de modo indissociável, sociedade e família. Porém, a mudança de hábitos não acompanha o ritmo da transformação de

1 Artigo derivado da Dissertação de Mestrado do primeiro autor, sob a orientação da segunda autora, defendida em 2003.

2 Endereço: Universidade Estadual Paulista Julio de Mesquita Filho (UNESP), Faculdade de Ciências e Letras, Av. Dom Antonio, 2.100, Assis, SP, Brasil 19806-900. E-mail: verapsic@terra.com.br

3 Deixemos aos historiadores a tarefa de precisar exatamente quando se iniciaram as transformações socioculturais que atingem a família contemporânea: Figueira (1987) atribui aos últimos trinta anos, o acelerado processo de modernização que ocorre no Brasil. Mas, há os que afirmam que este processo disparou logo após a Segunda Guerra Mundial. De nossa parte, assumimos a multiplicidade de fatores e acontecimentos históricos responsáveis por tais mudanças. O principal, entre eles, é a introdução da mulher no mercado de trabalho, ao lado de movimentos sociais, como o feminismo, que levaram-na a conquistar seus direitos. valores. Antes de assimilar o esboço de nova configuração familiar, modelado no processo que introduziu a mulher no mercado de trabalho, o homem é surpreendido pela ruptura da hierarquia doméstica e pelo constante questionamento de sua autoridade. Tais mudanças não contribuíram para reduzir o vazio instalado na rede de relações afetivas. O distanciamento entre o homem e os demais membros do núcleo familiar denuncia-se na fragilidade do vínculo estabelecido entre pai e filho, principalmente quando se trata de crianças do sexo masculino. Penetrar este silêncio e entender a questão do pai, tendo como eixo a identidade masculina, culturalmente determinada, tem sido tarefa de estudos, que colocam em perspectiva experiências contemporâneas de paternidade (Resende, 1997).

O modelo de família, organizado com base na hierarquia, regido pela severidade de princípios, é substituído por formas diferenciadas de organização, sem deixar lugar para o autoritarismo do antigo pai provedor, que exercia domínio sobre o grupo. A mulher, de modo submisso, tinha os afazeres da casa e o cuidado com os filhos, como ocupação exclusiva. Embora tais transformações repercutam na concepção de paternidade, subsistem, ainda, no imaginário social, marcas da estrutura tradicional. Não se trata apenas de colocar em questão determinado modelo familiar, e sim todos os referenciais de identidade individual, aos quais cada um tende a se moldar. Não há, talvez, em qualquer família, vigência de 
modelos homogêneos: contingências sociais, econômicas e culturais articulam-se aos fatores individuais e emocionais, reorientando a organização da família. Redefinem-se as relações internas e externas (Resende, 2001).

Adotar formas alternativas de convivência familiar torna-se, cada vez mais, prática freqüente em nossa sociedade. Criamse espaços para a manifestação diferenciada da paternidade (Hurstel, 1999). Se, de um lado, exigências sociais operam pulverizando a figura do provedor, de outro, as famílias buscam a se organizar, formando casais de dupla renda ou de dupla carreira. Emerge então nova figura paterna, não mais ancorada no poder econômico (Monteiro, 2001; Souza, 1994).

Tais movimentos, que atingem a vida e a intimidade de modo singular, introduzem tema não discutido no universo masculino, embora tenha feito, sempre, parte das preocupações femininas, por referir-se à fertilidade e à concepção. $\mathrm{O}$ homem conseguiu manter-se alheio a estas questões, como se fosse possível não ser atingido por elas. Diante do processo que fragiliza a figura do pai, ele se dá conta do risco de ser reduzido ao papel de mero reprodutor. Tanto pode ser utilizado por mulheres que desejam assumir a vida e a educação do filho, de forma independente, sem parceria masculina, como, também, pode submeter-se à tecnologia médica de reprodução humana e tornar-se pai sem dar consentimento, ou, como doador de sêmen, com desconhecimento da existência de um filho. São condições, que ameaçam seu direito de desejar, planejar e se organizar para ser pai, merecem estudo mais aprofundado.

Dada a complexidade envolvida na questão do pai, optamos por trabalhar com o pai presente, dentro de contexto familiar estável. A escolha se deve ao reconhecimento de que, mudanças estruturais da família tradicional não devem ser tidas, unilateralmente, como tendo caráter destrutivo. Não pretendemos restaurar o mito de uma estabilidade familiar, resultado de marcas inerciais pautadas pelo conservadorismo. Visamos a dar visibilidade ao aspecto positivo da atual fase de transição da família, de modo contrário à insistente abordagem reducionista de modelo patriarcal, monogâmico e nuclear, como assinala Barsted (1987).

Nosso interesse especifico é captar o movimento no qual o homem reinventa seu papel e constrói a subjetividade de pai com nova postura. Queremos encontrar a paternidade que acolhe e convive com o processo de transformações em marcha: o pai que transita entre valores novos e arcaicos. Questionam-se o silêncio e o distanciamento impostos por determinações culturais, através de várias gerações.

Cria-se, em tal perspectiva, oportunidade para dar a palavra ao pai. De início, fazemos incursão na teoria que ancorou a condução deste trabalho e, em seguida, descrevemos o caminho que permitiu dialogar com homens que se percebem neste novo contexto. No final, resgatamos fragmentos de suas falas, colhidas nas entrevistas.

\section{A presença do pai}

Há vários caminhos pelos quais é possível abordar a questão masculina. A idéia de extrair o tema da paternidade surgiu da experiência clínica, em que a figura paterna transita em meio às situações terapêuticas de forma variada, seja por meio de sua concreta presença ou de sua efetiva ausência da vida do paciente, seja por meio de projeções que os pacientes fazem de diversos pais internalizados, ou de representações de pai. Cada qual construiu, a seu modo, o pai institucional, o pai provedor, o pai protetor, o pai herói, forte e viril, pai frágil, pai omisso, entre outras.

Optamos por ultrapassar a discussão de outras possibilidades de encontro com a paternidade. Detemos nossa atenção na figura de um pai real, presente em sua corporalidade e afetividade, que se depara com a demanda subjetiva, advinda da exigência de revisão de seu papel no mundo contemporâneo. Trata-se de abordagem que não estabelece dicotomia entre as dimensões subjetiva e cultural, respeita seus entrelaçamentos e enfatiza o papel que a figura paterna desempenha na estruturação psíquica da criança. O pai, que enfocamos, tem conflitos em relação a suas figuras parentais.

Por este recorte, a entrada se faz pela via do conhecimento psicanalítico, sem propor leitura do inconsciente do pai, mas a apropriação de dispositivos que permitem compreender sua transformação subjetiva. Convém, antes, clarificar, um pouco mais, o entendimento do homem como pai, cuja imagem guarda resquícios de sua origem na atividade familiar do patriarca colonial. Costa (1983), nos auxilia a resgatar o pai antigo, proprietário de bens, escravos e filhos, disposto a impor sua lei e seus direitos e a resguardar seu nome e sua honra. Autoritário, se isentava de maiores compromissos e de manifestações afetivas para com os filhos, cuja relação era marcada pela idéia da diferença, como afirma Figueira (1987), ao se referir à hierarquia familiar: "adulto é diferente de criança, está na posição de quem sabe 'mais e melhor', $e$ pode - e mesmo deve - de quando em quando, mostrar seu poder através do exercício legitimo da disciplina" (Figueira, 1987, p. 15).

O pai exercia o poder na casa, com força para manter o círculo vicioso em que a família estava secularmente encerrada. Sua autoridade valia tanto para os filhos como para a mulher, que dele dependia economicamente e a quem se submetia de acordo com as regras estabelecidas. A importância do pai, do patrimônio e da religião reduziu, expressivamente, o espaço físico e sentimental da criança ${ }^{4}$.

Com um número de mulheres cada vez maior ingressando no mercado de trabalho e conquistando a independência econômica, ocorreram novos arranjos familiares, com significativa mudança nas relações entre homens e mulheres, como a separação entre papéis conjugais e papéis parentais (Moraes, 2001).

Novo perfil de pai foi se esboçando:

É um homem oriundo das classes médias ou altas, que se beneficia de uma formação e de uma renda mais elevada que a média. Tem uma profissão liberal que lhe permite, bem como à sua mulher, dispor livremente de seu tempo e rejeita

4 Do ponto de vista da propriedade, a criança era um acessório supérfluo. Ao pai-proprietário interessava o filho adulto, com capacidade para herdar seus bens, levar adiante seu trabalho e enriquecer a família. A organização socioeconômica familiar e o saber passadista que a estruturava relegavam a criança a uma espécie de limbo cultural em que permanecia até a puberdade. Cimentando estes dois fatores encontravase a visão religiosa da cultura. Entre o adulto e a criança, as ligações existentes eram a da propriedade e da religião, fora disso o fosso os separava (Costa, 1989). 
a cultura masculina tradicional. A maioria se diz em ruptura com o modelo de sua infância e não quer, por nada, reproduzir o comportamento do pai, considerado "frio e distante". Eles almejam "reparar" sua própria infância. Finalmente, vivem com mulheres que não têm vontade de ser mães em tempo integral. (Badinter, 1992, p. 172)

Mas, é impossível descrever o homem sem tanger aspectos relativos à virilidade, nem falar do pai sem tocar na questão da paternidade, por serem temas que ajudam a compor tanto a imagem de pai, como o perfil do novo homem, ou da nova maneira de percebê-lo. O sexo que identifica a criança, ao nascer, não garante ao homem a identidade masculina; tendemos a lidar com a feminilidade como um dado da natureza, e com a masculinidade como uma conquista cultural. Dizer de modo imperativo a alguém: "seja homem" não tem a mesma conotação do "seja mulher"; o homem sempre enfrenta o desafio de provar sua virilidade (Badinter, 1992).

\section{Pai e função paterna}

É pressuposto da teoria psicanalítica o papel estruturante do pai, a partir da instauração do complexo de Édipo. $\mathrm{Na}$ trama familiar, o sujeito se constrói e sai do estado de natureza para ingressar na cultura. A experiência clínica tem mostrado que, na vida adulta, as representações dessa vivência insurgem nas várias possibilidades de construção psico-afetiva, com repercussão nas relações sociais. É importante resgatar a leitura que Arminda Aberastury (1991) faz das condições, nas quais, Freud elaborou o conceito do complexo de Édipo, ao tomar a denominação da obra de Sófocles 5 . Segundo a autora, o pai da psicanálise teria, inconscientemente, deformado o texto do dramaturgo grego quando deixou de destacar na figura de Laio, pai de Édipo, o papel que desempenhou no cumprimento do destino do filho ${ }^{6}$. "Com efeito, Freud tomou em conta somente a situação do menino frente a seus pais e eludiu - ou reprimiu - o que os pais sentem e atuam em relação a seus filhos" "7 (Aberastury, 1991, p. 43, grifo nosso).

O pai representa a possibilidade do equilíbrio pensado como regulador da capacidade da criança investir no mundo real. A necessidade da figura paterna ganha contornos

5 Na lenda grega do Rei Édipo, "tendo sido condenado pelo destino a matar seu pai e desposar sua mãe, faz todo possível para escapar à predição do oráculo, mas não consegue e se castiga arrancando-se os olhos quando averigua que sem saber cometera os dois crimes que lhe haviam sido preditos" (Aberastury, 1991, p. 43).

6 "Laio foi desterrado de Tebas por sua vida dissoluta. Refugiou-se em Pélope cujo rei confiou-lhe a educação de seu filho Crisipo. Laio educou Crisipo, mas também o perverteu iniciando-o no homossexualismo e desapareceu de Pélope, fato que fez que o pai de Crisipo amaldiçoasse-o pelo rapto de seu filho. Pediu que Laio nunca tivesse um filho, e se tivesse, que a morte o atingisse através dele. Após casar-se com Jocasta e ao nascer Édipo, consultou um oráculo que lhe confirmou a maldição dizendo que seria morto pelo filho e este casaria com a mãe. Para escapar do oráculo quis matar o filho pendurando-o pelos pés no monte Citerão" (Aberastury, 1991, p. 45).

7 Arminda Aberastury explica que Freud descartou do grupo de neuroses da tragédia sofocliana, o parricídio e o homossexualismo, "ao aceitar somente um aspecto caiu na repressão de determinados conflitos que o afetavam" (Aberastury, 1991, p. 45). no processo de desenvolvimento, de acordo com a etapa da infância. Sua atuação na fase inicial da vida é decisiva na resolução de conflitos em dois momentos importantes do desenvolvimento: o primeiro, entre seis e doze meses, quando a criança se vê inserida no triângulo edípico, denominado organização genital precoce. O segundo período é marcado pela entrada na adolescência, quando a maturação genital obriga a criança a definir seu papel na procriação. A totalidade de suas experiências com os pais e com o mundo externo, neste momento, tende a orientar uma forma especial de desejar e, mais tarde, de conceber e se relacionar com um filho (Aberastury, 1991).

A criança necessita do par conjugal adulto para construir dentro de si imagem positiva das trocas afetivas e da convivência. Durante o desenvolvimento da personalidade, o pai real se sobressai e ganha consistência quando a criança o percebe enquanto desejo da mãe e objeto daquilo que o filho está apto a apreender dele, estabelecendo uma dialética.

Embora o lugar do pai no grupo etário infantil, entre seis e doze meses, não seja tão destacado na literatura, como acontece com a figura materna, sabe-se que o contato corporal entre o bebê e o pai, no cotidiano, é referência na organização psíquica da criança, devido à sua função estruturante no desenvolvimento do ego. No segundo ano de vida, quando já existe a imagem de pai e de mãe, a figura paterna ganha relevo, não só para ancorar o desenvolvimento social da criança, mas para servir de suporte das dificuldades inerentes ao aprendizado deste período. É este apoio que vai alavancar o desprendimento da criança da estrutura doméstica confortável, até então, garantida pela mãe. O movimento para alcançar autonomia, ganha maior força na adolescência (Aberastury, 1991).

Raissa Cavalcante (1995), analista junguiana, sustenta que o arquétipo ${ }^{8}$ do pai, vivenciado através da encarnação no pai real, é o símbolo que promove a estruturação psíquica da criança e lhe permite abrir-se para horizonte de novas possibilidades. Neste sentido, a identificação da criança com o universo de seu pai se dá através da experiência da interação, quando ele aparece como interdito na relação urobórica ${ }^{9}$ entre mãe e filho. Sua presença marca, simbolicamente, a dinâmica de rompimento desta fase (Gomes, 2003).

Corneau (1991), nas pegadas de Lacan, ressalta que o pai é o primeiro outro que a criança encontra fora do ventre de sua mãe: ele é indistinto para o recém-nascido, mas ao bloquear o desejo incestuoso, sua figura vai se diferenciando, permitindo o nascimento da interioridade do filho e desfaz, assim, a fusão entre o eu e o não eu: “(...) o pai encarna inicialmente a não mãe e dá forma a tudo que não seja ela" (Corneau, 1991, p. 27).

É esta a presença que irá facilitar à criança a passagem do mundo da família para o da sociedade. Será permitido o

8 A psicologia junguiana define os arquétipos como “(...) fatores e motivos que coordenam elementos psíquicos no sentido de determinadas imagens (que devem ser denominadas de arquétipos) e isso sempre de maneira que só é reconhecido pelo efeito. Eles existem pré-conscientemente e formam provavelmente as dominantes estruturais da psique em si" (Jacobi, 1957, p. 37).

9 "urobóros, a serpente circular que morde a própria cauda, engolindo-a, caracteriza simbolicamente a unidade sem opostos de uma realidade psíquica" (Neumann, 1980, p. 11). 
acesso à agressividade, à afirmação de si, à capacidade de se defender e de explorar o ambiente: "as crianças bem paternizadas sentem-se seguras em seus estudos, na escolha de uma profissão ou na tomada de iniciativas pessoais" (Corneau, 1991, p. 28). Apesar da importância da figura paterna, o homem, em vias de se tornar pai, tende a se fragilizar diante da nova responsabilidade. Bernard This (1987) exemplifica esta passagem com a experiência afetiva do homem, cuja inquietação o levou a indagar a respeito dos sonhos e sentimentos que surgem na espera do nascimento do filho.

O nascimento do filho desperta no homem desejos inconscientes e fantasias relacionadas à morte e a situações ligadas à resolução de conflitos parentais. "É por isso que, ainda que desejado pelo homem, feliz em ser pai, o nascimento se anuncia e é vivido num clima emocional que varia segundo o tempo e os indivíduos; cada homem reage à sua maneira" (This, 1987, p. 96).

O autor critica a tendência comum, entre nós, de promover abusivamente o imaginário do "bom pai", figura ideal a ser assumida por todos os homens em instância de paternidade. A criança que nasce, adverte, tem necessidade de seu pai e de sua mãe, com quem deverá conviver. Ao promover o ideal de parentalidade (bons pais, ou pais perfeitos), corremos o risco de esmagar os seres humanos sob o peso do imaginário que afoga toda vida e todo desejo. O pai "imaginário" não é o pai "real", felizmente (This, 1987, p. 96).

A esta trama acrescentamos, ainda, o poder afetivo materno que supera o do pai e estabelece contraponto na dinâmica da família, sem que os envolvidos se dêem conta do pacto silencioso dessa relação. É como se mãe e filho quisessem prolongar a "parceria" que um dia existiu entre eles, na fase inicial da vida. Não podemos afirmar que se trata de dificuldade compulsiva da mãe para com seus interesses próprios ou, no outro extremo, pela preocupação excessiva e patológica com o filho, embora isto possa ocorrer, corrobora para excluir a figura paterna.

\section{Metodologia}

O pai contemporâneo, objeto desta reflexão, não se identifica com o homem que definimos ser mero reprodutor, ou provedor econômico: ele se faz presente em contexto familiar estável, sob o ponto de vista da estrutura e da dinâmica do grupo familiar. Está sujeito e é movido pelas transformações sócio culturais. Dispõe-se a redefinir seu papel, a restabelecer seu lugar e a repensar modelos que lhe permitam viver a paternidade, senti-la e exteriorizá-la. O processo que leva este homem, agora alojado neste novo papel, a construir a subjetividade de pai, e a instrumentar-se para enfrentar novas demandas, é a questão que buscamos, aqui, compreender e explorar.

$\mathrm{O}$ acesso a este conhecimento se deu através do método clínico de pesquisa, com apoio da psicanálise. Não se trata de submeter ao tratamento psicanalítico as pessoas que se dispuseram a colaborar, mas aplicar seus conceitos na interpretação de fenômeno que tem dimensão subjetiva e também, social. O uso de paradigma distante do modelo tradicional de produzir ciência tem como preocupação não ordenar dados, mas sistematizar experiências de vida, permitir que o objeto se desvele, tanto mais o pesquisador, dele, conseguir aproximar-se. Portanto, não houve a pretensão de alcançar resultados que contemplassem toda a população de homens, cujas companheiras trabalham e com elas dividem as tarefas domésticas, nem de produzir certezas acerca da intrincada relação que eles estabelecem com o grupo familiar.

O método de pesquisa, por nós adotado, não comporta observações que validem ou refutem a teoria, mas, a partir de escuta diferenciada, permite que se descubram pistas para idéias originais a respeito do papel paterno, da transformação da paternidade e da figura masculina. Retomamos o princípio fundamental no método desenvolvido por Freud, no qual, as elaborações mentais de seus analisandos exerciam impacto sobre ele e contribuíam tanto para sua auto-análise, como para o desenvolvimento da teoria. Assim, entendemos que de forma similar, o método clínico de pesquisa oferece oportunidade tanto ao pesquisador, como ao entrevistado, de conhecer $o$ aspecto da realidade que os cerca, ao mesmo tempo em que se revela o conhecimento sobre o objeto pesquisado:

O julgamento clínico é conseqüência natural da permissão que o psicólogo se concede de usar os recursos de sua mente para avaliar os dados de um caso, e é o que decide, em última instância, sobre a importância e significado dos dados. (Trinca, 1984, p. 20)

Evidentemente há diferenças, pois, no par terapêutico, o estabelecimento do processo analítico coloca o analista diante de articulações dessa relação intersubjetiva como figura consciente e inconscientemente participante. Faz par com o processo de conhecimento do tipo compreensivo, que se vale da intersubjetividade da relação pesquisador-participante.

Evidencia-se, portanto, a relação intersubjetiva concebida pela psicanálise, manifestada nas articulações da ambivalência do complexo pai e inserida na ordem de uma relação que objetiva se deparar com a subjetividade paterna que aparece não como absoluta, mas clivada, ou seja, originária da subjetividade e dos aspectos conscientes ou inconscientes da experiência. Supomos que a ambivalência do complexo pai encontrará na relação intersubjetiva, pesquisador-participante, seu lugar de manifestação, e como tal, aparecerá no lugar do desconhecido e não no lugar da verdade cartesiana. Por isso, vale reafirmar, não procuramos uma verdade paterna, mas uma paternidade que se inscreve na relação intersubjetiva, que tem como marca a ambivalência do complexo pai.

Adotamos a entrevista como principal instrumento e a análise qualitativa enquanto estratégia, porque permite dar relevância à fala do entrevistado e dela extrair o dado significativo para nossas indagações. A informação pode vir expressa em um aspecto da estória narrada pelo entrevistado, em seu ato de reconhecimento da existência de problemas, em eventuais insights, ou até no modo como se estabeleceram relações entre entrevistador e entrevistado (Vizzoto, 1994). Não é a veracidade da narrativa que conta, mas a verdade do entrevistado que sabe, percebe-se e é percebido como pai neste novo contexto.

$\mathrm{O}$ roteiro norteador das entrevistas foi elaborado com o objetivo de colher informações que descrevessem e avaliassem a relação do entrevistado com o pai, a forma como percebia o exercício da paternidade na família contemporânea; o redimensionamento do papel paterno, a desconstrução e 
reconstrução da paternidade; os sentimentos do entrevistado diante do novo papel.

Embora o estudo do pai presente deva incluir a dinâmica de suas relações com filhos, esposa e figuras parentais de origem, nossa opção foi criar espaço exclusivo para ele se manifestar, dar-lhe voz, envolvê-lo em suas próprias tramas, convidando-o a percorrer sua trajetória paterna. As entrevistas foram realizadas individualmente, na casa dos participantes, sem a presença de qualquer membro da família, gravadas em áudio com transcrição dos relatos.

Foram entrevistados dois pais, mediante a formalização da participação livre e consentida, a fim de garantir condições éticas necessárias ao trabalho. Os participantes foram indicados por pessoas conhecidas, que acompanhavam nosso interesse e se dispuseram a colaborar voluntariamente, sendo este requisito estabelecido inicialmente. Pertencem à faixa etária entre 30 e 40 anos, do extrato social descrito como classe média. Possuem nível universitário e fazem parte de contexto familiar formado pelo casamento estável, sendo que as esposas possuem também curso superior e todos seguem carreiras profissionais estruturadas, partilham o orçamento, as responsabilidades da casa. Caracteriza-se, portanto, situação familiar de dupla renda.

Convém explicitar a diferença entre dupla renda e dupla carreira. A família de dupla renda se caracteriza pelo trabalho remunerado do par conjugal e preserva o modelo tradicional de divisões de papéis. O casal de dupla carreira também constitui uma família de dupla renda e dela se distingue, pelo envolvimento com a carreira profissional, ao mesmo tempo em que se preocupa com a manutenção da vida afetiva e familiar. O que marca a diferença no casal de dupla carreira em relação ao casal de dupla renda, é o interesse manifestado nas atitudes de partilha e igualdade, que rompem padrões tradicionais da família. Abre-se espaço para redimensionar o papel do pai e, por extensão, o da mãe, uma vez que são postas em evidência características de relacionamento do casal nesses núcleos inovadores (Monteiro, 2001; Souza, 1994). Sabemos que a realidade muda e desejamos apreender nosso objeto no processo de transformação. Não cabe, portanto, fixá-lo em um segmento etário ou social, mas criar estratégia para que ele possa emergir da fala de quem o produz.

\section{Resultados}

\section{Fragmentos de estudo sobre a (re)construção da paternidade}

(...) a proposta de explorar o pai por ele mesmo, confrontá-lo com o imaginário paterno e vê-lo surgir através dessa opaca névoa que cobre seu mundo, não só enriquece o estudo da paternidade com novas perspectivas, como também contribui para um rompimento do silêncio histórico do homem e do pai. (Gomes, 2003, p. 16)

A entrevista nos permitiu captar o sentimento que acompanhava a descrição da experiência de cada participante. Com certo desconforto, reconheceram que seus pais tiveram dificuldade para deixar fluir e circular o afeto que, certamente, eles nutriam pelos filhos. Estes percebiam o bloqueio inexplicável e desconheciam as razões que os mantinham distantes.
O relacionamento frio fez parte da infância e da adolescência, e os fez desejar um pai diferente e idealizado:

(...) se falassem: você quer trocar de pai, eu diria troco, porque eu queria outro pai e não esse. É estranho por que não é o normal, não que eu não goste dele, mas queria que fosse diferente, fosse de outro jeito, tivesse outro tipo de relação, principalmente que primasse pelo diálogo.

O segundo participante ressaltou que foi mal sucedido em seu esforço para se identificar com seu genitor, para se aproximar dele, e para se sentir aceito e reconhecido: “(...) minha relação com o meu pai eu gostaria que fosse mais próxima, ter ele mais perto e que ele fosse mais carinhoso e ele não era (...), eu desejava que fosse diferente..."

Ambos os entrevistados identificaram a contradição que, embora os tenha feito entrar em conflito com seus sentimentos, teve, também, uma finalidade que lhes era útil no sentido de os estimular a resistir ao papel que sempre lhes foi culturalmente imposto. Sentiram-se encorajados para recriá-lo e afastarem-se do modelo que os acompanhou desde a infância. No lugar de filhos, reconheceram que, sem esforço próprio, não conseguiriam modificar a estrutura do relacionamento do homem com a família, e torná-lo mais favorável devido à atitude conformista dos envolvidos, que vivem e entendem esta dinâmica como dada pela natureza.

Na verdade, os entrevistados admitiram que a identidade masculina não pode ser atrelada a valores, que negam ao homem o direito de sentir e de se emocionar. Talvez este seja o principal diferencial do pai contemporâneo, que merece ser destacado neste estudo: ele se dispõe a reconhecer seus sentimentos e a estabelecer confronto com imposições do papel masculino, traduzido como expressão de império machista, difundido pelos homens e apoiado pelas mulheres, como o sentimento contido na seguinte expressão:

Eu estava com o meu pai, ou melhor, eu estava sozinho num ponto de ônibus e vi um pai e um filho, ofilho era grande alto e o pai velhinho e grande... O filho disse: tchau pai e lhe deu um beijo, naquele dia eu chorei sozinho, se meu pai fizesse isso comigo seria mais fácil.

Atualmente, reconhecem que não se tratava, apenas, de adotar atitude contrária à do pai, mas de admitir os próprios sentimentos e sua ambivalência: Toda relação é marcada pelo amor e pelo ódio, e embora tais sentimentos façam parte do pai real, não são eles que determinam a autoridade e a distância. Uma atitude amorosa e atenciosa com o filho, acariciá-lo e ser por ele acariciado, contribuiria para afastar o fantasma homossexual subjacente no jogo afetivo. Buscando compensar o afeto que lhes foi negado, construíram a imagem de pai ideal, na qual deveriam se transformar mais tarde: ao ocupar o lugar de pais, tentam assumir paternidade ligada mais ao afeto, à partilha e ao diálogo, seja com os filhos, seja com a esposa.

Entendem que ao se permitirem o reconhecimento da própria sensibilidade, transformaram-se em pessoas privilegiadas, com direito a atender necessidades da vivência paterna atual: é este o sentimento que impulsiona a mudança, daí adotarem atitudes que correspondem ao modelo que lhes parece ser ideal, que é a conquista de seu próprio espaço afetivo: 
Isso é verdade, eu não tinha pensado dessa forma antes, dá vontade de falar isso para ele (pai), falar do espaço que ele não teve... Quanto mais você convive, mais você ganha, quanto mais você dá mais rico você fica e ele não teve essa experiência, ele se fechou nessa experiência.

Quando falam de si e expõem sentimentos e emoções, rompem com o que Corneau denomina "silêncio hereditário dos homens"; falam de seus pais, rememoram seus sentimentos de raiva, tristeza e mágoa (Corneau, 1991, p. 188). Reconhecem mudanças no modo atual de lidar com os sentimentos na relação com a esposa e com seus filhos:

\begin{abstract}
Eu digo que estou muito melhor depois de meus filhos, eu aprendi muito com eles, sou incapaz de certas coisas, aprendi com os meus filhos... por exemplo, eu sou sensível a qualquer tipo de injustiça, isso me incomoda muito, por exemplo, a relação com meu pai, você tem um outro que não é você, mas ao mesmo tempo é você também, você fica pensando que as injustiças que possam fazer contra ele, você jamais desejaria de alguma forma, todo mundo tem um pai, para que ser injusto com alguém, nada melhor do que ser mais sensivel com a própria vida.
\end{abstract}

Ao se revelarem enquanto homens dotados de sensibilidade e favorecidos por se reconhecerem nela, julgam conciliar a necessidade paterna atual que imprime em suas vidas o desejo de superar a dificuldade que sempre fez parte da infância. Tais manifestações nos levam a pensar que a figura do pai contemporâneo se constitui em base sensível, que respeita a capacidade do homem de perceber e de reconhecer suas necessidades afetivas, embora se verifique a multiplicidade de fatores, que se conjugam em sua composição.

Admitiam ter o que dizer sobre seus pais, mas se referiam a eles com admiração e ao mesmo tempo com certo desconforto, diante de conflitos relembrados:

O que eu sentia é que meu pai era mais ausente em relação aos filhos, participava menos, ele era provedor pagava tudo, comida, cuidava das finanças e só nos momentos críticos ele aparecia, quando alguém ficava de segunda época, por exemplo, mas isso era bem de fundo, pois quem batia era minha mãe, mas ele falava alguma coisa na hora de fazer planos para estudar em algum lugar, ai ele aparecia, mas como pano de fundo, não ativo como eu sou com os meus filhos.

O afeto que esteve presente na descrição das relações com a figura paterna deu relevância à presença da figura materna, que até então, os entrevistados pareciam não se dar conta. Ambos observaram que a mãe sempre desempenhou o papel de mediadora das relações pai-filho, interpondo-se entre os dois, buscando apaziguar eventuais conflitos. Nos discursos, sua figura aparece sempre associada a sentimentos de amor, raiva ou medo e à intimidade, enquanto a figura paterna é lembrada como alguém que se mantinha distante, despojado de qualquer possibilidade de uma relação mais íntima.

O poder afetivo da mãe merece ser destacado porque, se de um lado, ela atuava como mediadora da relação pai-filho, de outro, ela se convertia em obstáculo para o intercurso do afeto entre eles. $\mathrm{O}$ espaço afetivo que ela ocupou na vida dos filhos se contrasta com o lugar que ela própria concedia ao pai deles. Este, por sua vez, não reivindicava sua participação:

Muitas vezes eu me questionei se ela não fazia questão da proteção, de manter os filhos próximos... Às vezes meu pai era o que era, mas também era incentivado pela minha mãe a ser o que era... Era aquela coisa de ter o filho, a minha mãe tinha, era exagerada, ela podia ter os filhos, porque o pai não?

A partir daí é possível questionar se o distanciamento do pai se deve unicamente a auto-exclusão ou a apropriação do filho, por parte exclusiva da mãe? Ele teria sido impedido de se aproximar, ou não reconhecia em si o desejo de se aproximar do filho e com ele trocar afeto? Por que seria tão fácil a mãe se relacionar tão intimamente com a criança, manter-se tão próxima dela, sem incluir o pai? Até onde tais condições são produzidas por determinações culturais, mas acolhidas pelo homem como intrínseca à condição paterna? "Nossos pais talvez não tenham lutado para conquistar o próprio espaço, culturalmente havia várias coisas inviabilizando, até pela comodidade".

Não há uma construção linear de paternidade. O modelo tradicional vai, progressivamente, se desarticulando conforme o homem, ao se tornar pai, se permitir reviver neste papel a relação com o pai da infância, resignifica sua experiência e percebe o encontro de seus sentimentos antigos com os atuais.

Assim, se desvela a figura paterna renovada que se construiu e se compôs na trama das relações entre o jovem pai e o par parental original, agora atualizada na interação com a nova família. Trata-se de um pai mais presente e identificado com as exigências contemporâneas da família, que expõe sua face afetiva e próxima da intimidade cotidiana, de modo oposto à concepção tradicional que exigia distanciamento físico e afetivo. Acreditamos, portanto, que é no âmago dos sentimentos paternos de cada homem, e na teia de relações que eles estabelecem com o complexo-pai (o pai real ou imaginário) que é possível a construção e reconstrução da subjetividade de pai.

\section{Considerações Finais}

A disposição dos participantes para colaborar com a entrevista mostra a oportunidade criada para a construção de um espaço masculino de discussão de temas, prática pouco comum neste universo. Acima da preocupação em manter atitude contrária a de seus pais, observamos a necessidade de falar do pai, amoroso, atencioso e presente, e, principalmente, capaz de aproximar-se fisicamente do filho. A experiência com a ausência de uma figura paterna calorosa, que conseguia alimentar a imagem de pai severo e autoritário, levou-os a idealizar um pai mais tolerante e afetuoso, e a se proporem assumir este lugar.

As questões produzidas no campo familiar contemporâneo, que apelam para a humanização da figura paterna, tendem a suscitar atitude de reparação, que se expressa no esforço para justificar o humor e as atitudes de seus genitores e isentá-los da culpa pelo autoritarismo e pela ausência. Ao mesmo tempo em que reconheciam os problemas, colocavam-nos como vítimas da engrenagem que subjugou o pai 
provedor e exauriu suas forças. Recuperam a imagem do pai herói, que merece descanso, mas só permite mostrar sua face mais suave quando longe do combate, ou seja, quando se liberou de compromissos ligados à manutenção da família. Houve momentos em que, para justificar a distância paterna, os entrevistados se apropriaram do discurso do pai - tinham que trabalhar muito e por conta disso ficavam muito tempo fora de casa tendo suas forças exauridas por esse necessário esforço.

A mulher dona de casa, que apenas cuidava da família e exercia o papel de protetora, também se desvanece para dar lugar à companheira que, mesmo envolvida emocionalmente com os filhos, pode desincumbir-se do peso da excessiva presença materna. Os movimentos, que se observam em tempos de mutação e transição da paternidade, acenam para um futuro em que ao pai serão devolvidas, face ao bebê e à criança, a intrincada e ambivalente relação até aqui reservada à mãe. Ele não será um pai-mãe, como diria Parseval (1986), mas um homem-pai, ou mesmo, o homem reconciliado, que, no dizer de Badinter (1992), é aquele que encontrou seu pai e reencontrou sua mãe, isto é, tornou-se homem sem ferir o feminino-materno. Reconciliação supõe a idéia de uma dualidade de elementos que tiveram que se separar, e até que se opor, antes de se reencontrar. Leva em conta a noção de tempo, de etapas a superar, de conflitos a resolver. O reencontro do homem adulto com sua feminilidade original está nos antípodas do ódio de si que procede por exclusão. É verdade que o homem reconciliado não é educado no desprezo e no medo do feminino. Por isso o reencontro é menos difícil e dramático do que outrora. O homem reconciliado só pode nascer de uma grande revolução paternal. Esta, iniciada há apenas duas décadas, necessitará de várias gerações para concretizar-se plenamente. Ela clama por mudança radical nas mentalidades e profunda transformação nas condições da vida privada e profissional que, observamos, estão sendo tecidas nos núcleos familiares contemporâneos, a partir dos conflitos reestruturantes que nelas se manifestam.

\section{Referências}

Aberastury, A. (1991). A paternidade. Em A. Aberastury \& E. J. Salas, A paternidade: Um enfoque psicanalítico (pp. 41-87). Porto Alegre: Artes Médicas.

Badinter, E. (1993). XY: Sobre a identidade masculina. (M. I. D. Estrada, Trad.) Rio de Janeiro: Nova Fronteira.

Barsted, L. L. (1987). Permanência ou mudança: o discurso legal sobre a família. Em L. L. Barsted (Org.), Pensando a família no Brasil (pp.103-113). Rio de Janeiro: Espaço e Tempo.

Cavalcante, R. (1995). O mundo do pai: Mitos, símbolos e arquétipos. São Paulo: Cultrix.

Corneau, G. (1991). Pai ausente filho carente. (L. Jahn, Trad.). São Paulo: Brasiliense.

Costa, J. F. (1989). Ordem médica e norma familiar (2a ed.). Rio de Janeiro: Graal.

Figueira, S. A. (1987). Uma nova família? O moderno e o arcaico na família de classe média brasileira. Rio de Janeiro: Jorge Zahar.

Gomes, A. J. S. (2003). Paternidade contemporânea: Um estudo sobre o pai presente num contexto familiar estável. Dissertação de Mestrado, Universidade Estadual de São Paulo, Assis/SP.
Hurstel, F. (1999). As novas fronteiras da paternidade. (E. E. C. Castro, Trad.). Campinas: Papirus.

Jacobi, J. (1957). Complexo, arquétipo e símbolo (10 $10^{\mathrm{a}}$ ed.). São Paulo: Cultrix.

Monteiro, A. M. (2001). Avanços no estudo da conjugalidade: Os casais de dupla carreira. Psicologia: Ciência e Profissão, 21(3), 10-19.

Moraes, M. L. Q. (2001). A estrutura contemporânea da família. Em M. C. M. Comparato \& D. S. F. Monteiro (Orgs.), A criança na contemporaneidade e a psicanálise Vol. I Família e sociedade: Diálogos interdisciplinares (pp. 17-25). São Paulo: Casa do Psicólogo.

Neumann, E. (1980). A criança: Estrutura e dinâmica da personalidade em desenvolvimento desde o início de sua formação. São Paulo: Cultrix.

Parseval, G. D. (1986). A parte do pai. (T. C. Stummer \& L. A. Watanabe, Trad.) Porto Alegre: L\&PM.

Resende, V. R. (1997). A paternidade e o resgate da experiência humana do homem [Resumo]. Em UNESP (Org.), Anais, III Fórum de Debates em Extensão Universitária e Assuntos Comunitários (p. 46). Bauru: UNESP.

Resende, V. R. (2001). Avaliação da interação parental no desenvolvimento emocional [Resumo]. Em UEL (Org.), Anais do Congresso Iberoamericano de Psicologia Clínica e da Saúde. Avanços Recentes em Psicologia Clínica e da Saúde (p. 297). Londrina: UEL - APICSA.

Souza, R. M. (1994). Paternidade em transformação: O pai singular e sua família. Tese de Doutorado, Pontifícia Universidade Católica, São Paulo.

This, B. (1987). O pai: Ato de nascimento. Porto Alegre: Artes Médicas.

Trinca, W. (1984). Diagnóstico psicológico. A prática clínica. Em C. R. Rappaport (Org.), Temas básicos de psicologia (pp. 2533). São Paulo: E.P.U.

Vizzotto, M. M. (1994). Psicodinâmica da paternidade: um estudo sobre homens que esperam o nascimento de seu filho. Tese de Doutorado, Universidade Estadual de Campinas, Campinas.
Recebido em 16.12.2003

Primeira decisão editorial em 16.06.2004

Versão final em 19.07.2004

Aceito em 23.07.2004 